\title{
Vertical Vibration Characteristics of a Variable Impedance Pile Embedded in Layered Soil
}

\author{
Wenbing Wu, ${ }^{1,2}$ Xuelian Xu, ${ }^{1}$ Hao Liu, ${ }^{1}$ Changliang Fang, ${ }^{1,3}$ Bin Dou, ${ }^{1}$ and Rongzhu Liang ${ }^{1}$ \\ ${ }^{1}$ Engineering Research Centre of Rock-Soil Drilling \& Excavation and Protection, Ministry of Education, \\ China University of Geosciences, Wuhan, Hubei 430074, China \\ ${ }^{2}$ College of Civil Engineering and Architecture, Guangxi University, Nanning, Guangxi 530004, China \\ ${ }^{3}$ Institute of Drilling Engineering and Fluid Mining, TU Bergakademie Freiberg, Freiberg, Germany \\ Correspondence should be addressed to Changliang Fang; changliang.fang@tbt.tu-freiberg.de and Bin Dou; briandou@163.com
}

Received 30 September 2016; Accepted 21 February 2017; Published 3 April 2017

Academic Editor: Dane Quinn

Copyright (C) 2017 Wenbing Wu et al. This is an open access article distributed under the Creative Commons Attribution License, which permits unrestricted use, distribution, and reproduction in any medium, provided the original work is properly cited.

In engineering applications, various defects such as bulging, necking, slurry crappy, and weak concrete are always observed during pile integrity testing. To provide more reasonable basis for assessing the above defects, this paper proposed simple and computationally efficient solutions to investigate the vertical vibration characteristics of a variable impedance pile embedded in layered soil. The governing equations of pile-soil system undergoing a vertical dynamic loading are built based on the plane strain model and fictitious soil pile model. By employing the Laplace transform method and impedance function transfer method, the analytical solution of the velocity response at the pile head is derived in the frequency domain. Then, the corresponding semianalytical solution in the time domain for the velocity response of a pile subjected to a semisinusoidal force applied at the pile head is obtained by adopting inverse Fourier transform and convolution theorem. Based on the presented solutions, a parametric study is conducted to study the vertical vibration characteristics of variable cross-section pile and variable modulus pile. The study gives an important insight into the evaluation of the construction quality of pile.

\section{Introduction}

With the wide application of piles for supporting various upper structures all over the world, the construction quality of pile foundations has attracted increasing attention in recent decades. In practice, whatever the construction method is, various defects in pile are often found during pile integrity testing, such as bulging, necking, slurry scrappy, and weak concrete. The common methods for assessing the pile quality are static load testing and dynamic testing. Static load testing is inconvenient and time-consuming for a great deal of surcharge load is required to test the ultimate bearing capacity of pile foundation. Dynamic testing, including low-strain and high-strain testing, has been widely utilized in the nondestructive examination of pile due to its simplicity and reliability [1-4].

Since the pile dynamics is the basis of various methods of dynamic pile testing, many investigators have paid their attention to develop various dynamic interaction models for the dynamic response of pile subjected to vertical loads. Van Koten et al. [5] primarily utilized a distributed system of single Voigt unit (a linear spring and a dashpot connected in parallel) to simulate the soil reactions acting on the pile and derived an analytical solution for the dynamic interaction of pile-soil system. Following Van Koten et al's research, a large number of researchers applied this method to investigate the vertical vibration of pile foundation for different engineering conditions (e.g., Randolph and Deeks [6]; Michaelides et al. [7]; Yesilce and Catal [8]; Wang et al. [9]; Zhang et al. [10, 11]). Although the Voigt model is of great simplicity and high efficiency in practical engineering, it cannot allow for the wave effect of stress propagating in pile surrounding soil. Allowing more rigorous treatment of pile surrounding soil, Novak [12] developed the plane strain model assuming an elastic soil layer consisting of independent infinitesimally thin horizontal layers extending to infinity. The plane strain 
model has attracted numerous followings for lots of engineering cases, such as Rajapakse and Shah [13], Mamoon and Banerjee [14], El Naggar and Novak [15], Militano and Rajapakse [16], and Wu et al. [17]. It is worth noting that the plane strain model is one of the most important methods to simulate the interaction between pile and surrounding soil due to its compact and elegant properties; that is, there is zero strain in the vertical direction and the stress waves propagate only in the horizontal direction. In a different approach, Nogami and Novak [18] first adopted a threedimensional continuum model (i.e., the soil layer is threedimensional and its wave effect is considered) to investigate the vertical vibration of pile foundation. Afterwards, Nogami and Konagai [19], Senjuntichai et al. [20], $\mathrm{Hu}$ et al. [21], Wang et al. [22], Wu et al. [23, 24], and Zheng et al. [25, 26] also developed various three-dimensional continuum models extensively in their investigations on the dynamic response of pile-soil system. It can be found that the three-dimensional continuum model is theoretically more rigorous than the previously mentioned Voigt models and plane strain models. Nevertheless, it is very difficult to promote the use of these three-dimensional continuum models in layered soil because of its complexity.

Based on the above literature review, the main objective of this study is to develop simple and computationally efficient solutions for the analysis of vertical vibration characteristics of a variable impedance pile embedded in layered soil. In this paper, the dynamic interaction between pile and its surrounding soil is described by the plane strain model, and the dynamic interaction between pile and its underlying soil is simulated by the fictitious soil pile model [24]. Laplace transform and transfer function technique have been utilized to establish the impedance function of pile head in the frequency domain. By virtue of Fourier inverse transform, the semianalytical solution of the velocity response of pile head subjected to a semisinusoidal force is also obtained, this constituting the theoretical basis of the low-strain testing method of pile integrity. A parametric study is conducted to investigate the influence of pile properties on the vertical dynamic response of the variable impedance pile.

\section{Mathematical Model and Assumptions}

2.1. Computational Model. Considering the defects of pile and the inhomogeneity of soil, the vertical vibration of a variable impedance pile embedded in layered soil is theoretically studied based on the fictitious soil pile model. Figure 1 shows a schematic diagram of the pile-soil system, in which the finite soil layers underlying the pile end are assumed to be soil column, namely, fictitious soil pile whose cross-section area is the same as the pile. The fictitious soil pile is in perfect contact with the pile end and satisfies the plane section of deformation assumption. Taking into account the variation of modulus or cross-sectional dimension of the pile or soil properties, the pile-soil system is divided into a total number of $m$ along the vertical direction, which are numbered by $1,2, \ldots, j \cdots m$ from the bottom of fictitious soil pile to pile head. The properties of pile (including fictitious soil pile)

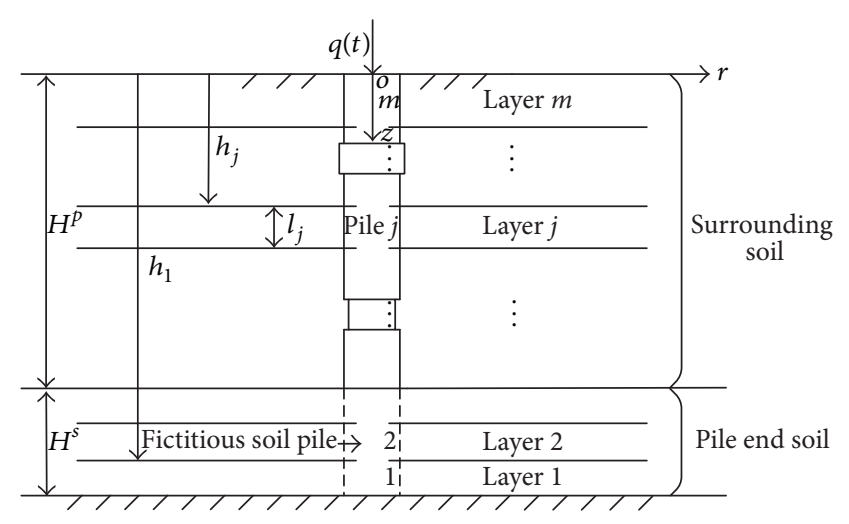

Rigid base

FIGURE 1: Schematic of pile-soil interaction model.

and surrounding soil layer are assumed to be homogeneous within each segment but may vary from segment to segment. $l_{j}$ and $h_{j}$ denote the thickness and top surface depth of the $j$ th pile-soil segment, respectively. $\rho_{p j}$ and $r_{j}$ represent the density and radius of the pile, respectively. $H^{p}$ and $H^{s}$ indicate the length of pile and the thickness of pile end soil, respectively. $q(t)$ defines the vertical exciting force acting on the pile head.

2.2. Underlying Assumptions. The pile-soil model is developed based on the following assumptions:

(1) The pile-soil system is subjected to small deformations and strains, and the pile and soil remain in perfect contact during the vibration. The stress and displacement of the interface of pile-soil system are continuous, and only vertical displacements are considered.

(2) The pile is vertical, viscoelastic, and cylindrical. The support conditions are based on the fictitious soil pile model that overlies rigid bedrock.

(3) The surrounding soil is isotropic linear viscoelastic medium with a hysteretic-type damping regardless of frequency. The surrounding soil is infinite in the radial direction and its free top surface has no normal or shear stress.

(4) The dynamic stress of soil transfers to the pile shaft through the complex stiffness on the contact surface of the every segment of pile-soil system.

(5) The conditions of displacement continuity and force equilibrium are satisfied at the interface of fictitious soil pile and pile end.

\section{Governing Equations and Their Solutions}

3.1. Dynamic Equation of Soil and Its Solution. Denoting $W_{j}=W_{j}(r)$ as the vertical displacement of the $j$ th soil layer, the dynamic equilibrium equation of the $j$ th soil layer 
undergoing vertical dynamic loading can be expressed as $[13,15]$

$$
r^{2} \frac{\mathrm{d}^{2} W_{j}}{\mathrm{~d} r^{2}}+r \frac{\mathrm{d} W_{j}}{\mathrm{~d} r}-\beta_{j}^{2} r^{2} W_{j}=0
$$

where $\beta_{j}=\mathrm{i} \omega / v_{s j} \sqrt{1+\mathrm{i} D_{s j}} ; v_{s j}=\sqrt{G_{j} / \rho_{j}}$ represents the shear wave velocity of the $j$ th soil layer, and $\rho_{j}, G_{j}$, and $D_{s j}$ indicate the density, shear modulus, and material damping of the $j$ th soil layer, respectively. $\omega$ denotes the circular frequency and $i=\sqrt{-1}$ depicts the imaginary unit.

Based on the theory of Bessel functions, the general solution of (1) is derived as

$$
W_{j}(r)=A_{j} K_{0}\left(\beta_{j} r\right)+B_{j} I_{0}\left(\beta_{j} r\right),
$$

where $I_{0}(\cdot)$ and $K_{0}(\cdot)$ represent the modified Bessel functions of order zero of the first and second kind, respectively. $A_{j}$ and $B_{j}$ are integration constants determined by boundary conditions. Based on assumption (3), it can be obtained that $B_{j}=0$ from (2).

The vertical shear stress at arbitrary point in the soil layer is written as

$$
\tau_{j}(r)=G_{j}^{*} \frac{\mathrm{d} W_{j}(r)}{\mathrm{d} r}=-G_{j}^{*} A_{j} \beta_{j} K_{1}\left(\beta_{j} r\right),
$$

where $G_{j}^{*}=G_{j}\left(1+\mathrm{i} D_{s j}\right)$.

Then, the vertical shear complex stiffness around the pile shaft of $j$ th soil layer is obtained as

$$
K K_{j}=\frac{-2 \pi r_{j} \tau_{j}\left(r_{j}\right)}{W_{j}\left(r_{j}\right)}=\frac{2 \pi r_{j} G_{j}^{*} \beta_{j} K_{1}\left(\beta_{j} r_{j}\right)}{K_{0}\left(\beta_{j} r_{j}\right)},
$$

where $I_{1}(\cdot)$ and $K_{1}(\cdot)$ represent the modified Bessel functions of order one of the first and second kind, respectively.

3.2. Dynamic Equation of Pile (Including Fictitious Soil Pile) and Its Solution. Denoting $u_{j}(z, t)$ as the vertical displacement of the $j$ th pile (including fictitious soil pile) segment, the dynamic equation of pile can be expressed as

$$
\begin{aligned}
& E_{p j} A_{p j} \frac{\partial^{2} u_{j}(z, t)}{\partial z^{2}}+A_{p j} \delta_{p j} \frac{\partial^{3} u_{j}(z, t)}{\partial z^{2} \partial t}-m_{p j} \frac{\partial^{2} u_{j}(z, t)}{\partial t^{2}} \\
& -f_{j}(z, t)=0,
\end{aligned}
$$

where $E_{p j}, m_{p j}, \delta_{p j}$, and $A_{p j}=\pi r_{j}^{2}$ represent the elastic modulus, mass per unit length, viscous damping coefficient, and cross-section area, respectively. $f_{j}(z, t)=K K_{j} u_{j}(z, t)$ depicts the frictional force of the $j$ th soil layer acting on the surface of the pile shaft. $K K_{j}$ denotes the vertical shear complex stiffness around the $j$ th pile segment.

Boundary condition at the top of pile can be expressed as

$$
\begin{aligned}
& {\left.\left[E_{p m} A_{p m} \frac{\partial u_{m}(z, t)}{\partial z}+A_{p m} \delta_{p m} \frac{\partial^{2} u_{m}(z, t)}{\partial z \partial t}\right]\right|_{z=0}} \\
& \quad=-q(t) .
\end{aligned}
$$

Boundary condition at the bottom of fictitious soil pile can be written as

$$
\left.u_{1}(z, t)\right|_{z=h}=0 .
$$

Continuity conditions of the interface of the adjacent pile or fictitious soil pile segments can be founded as

$$
\begin{aligned}
u_{j}(z, t) & =u_{j+1}(z, t) ; \\
E_{p j} A_{p j} \frac{\partial u_{i}(z, t)}{\partial z} & =E_{p j+1} A_{p j+1} \frac{\partial u_{p j+1}(z, t)}{\partial z} .
\end{aligned}
$$

Initial conditions of pile and fictitious soil pile segments can be derived as

$$
\begin{gathered}
\left.u_{j}(z, t)\right|_{t=0}=0 \\
\left.\frac{\partial u_{j}(z, t)}{\partial t}\right|_{t=0}=0 .
\end{gathered}
$$

Denoting $U_{j}(z, s)=\int_{0}^{\infty} u_{j}(z, t) e^{-s t} \mathrm{~d} t$ as the Laplace transform of $u_{j}(z, t)$ with respect to time and combining with the initial conditions (9), (5) is transformed by applying the Laplace transform (two-sided) as follows:

$$
\begin{aligned}
& E_{p j} A_{p j} \frac{\partial^{2} U_{j}(z, s)}{\partial z^{2}}+A_{p j} \delta_{p j} s \frac{\partial^{2} U_{j}(z, s)}{\partial z^{2}} \\
&-m_{p j} s^{2} U_{j}(z, s)-K K_{j} U_{j}(z, s)=0 .
\end{aligned}
$$

Equation (10) can be further reduced as

$$
\begin{aligned}
V_{p j}^{2}\left(1+\frac{\delta_{p j}}{E_{p j}} s\right) \frac{\partial^{2} U_{j}(z, s)}{\partial^{2} z} \\
\quad-\left(s^{2}+\frac{1}{\rho_{p j} A_{p j}} K K_{j}\right) U_{j}(z, s)=0,
\end{aligned}
$$

where $V_{p j}, \rho_{p j}$, and $E_{p j}$ denote the elastic longitudinal wave velocity, density, and elastic modulus of the $j$ th pile (including fictitious soil pile) segment, respectively.

The general solution of (11) can be expressed as

$$
U_{j}(z, s)=C_{j} \cos \left(\frac{\bar{\lambda}_{j} z}{l_{j}}\right)+D_{j} \sin \left(\frac{\bar{\lambda}_{j} z}{l_{j}}\right)
$$

where $\left.\bar{\lambda}_{j}=\sqrt{-\left(s^{2}+K K_{j} / \rho_{p j} A_{p j}\right) t_{j}^{2} /\left(1+\left(\delta_{p j} / E_{p j}\right) s\right.}\right)$ illustrates dimensionless eigenvalue. $C_{j}$ and $D_{j}$ are constants determined by the boundary conditions. $t_{j}=l_{j} / V_{p j}$ depicts the propagation time of elastic longitudinal wave in the $j$ th pile (including fictitious soil pile) segment. $T_{c}$ denotes the propagation time of elastic longitudinal wave propagating from the pile head to the pile end. 
Combining with (7), the displacement impedance function at the top of the first fictitious soil pile segment $\left(z=h_{1}\right)$ can be obtained as

$$
\begin{aligned}
& \left.Z_{p 1}\right|_{z=h_{1}} \\
& =\frac{-\left.\left[E_{p 1} A_{p 1}\left(\partial U_{1}(z, s) / \partial z\right)+A_{p 1} \delta_{p 1} s\left(\partial U_{1}(z, s) / \partial z\right)\right]\right|_{z=h_{1}}}{\left.U_{1}(z, s)\right|_{z=h_{1}}} \\
& =-\frac{\rho_{p 1} A_{p 1} V_{p 1}\left(1+\left(\delta_{p 1} / E_{p 1}\right) s\right) \bar{\lambda}_{1} \tan \left(\bar{\lambda}_{1}-\phi_{1}\right)}{t_{1}}
\end{aligned}
$$

where $\phi_{1}=\arctan \left(Z_{p 0} t_{1} / \rho_{p 1} A_{p 1} V_{p 1} \bar{\lambda}_{1}\left(1+\left(\delta_{p 1} / E_{p 1}\right) s\right)\right) . Z_{p 0}$ denotes the displacement function at the bottom of the fictitious soil pile.

Then, following the method of recursion typically utilized in the transfer function technique [9], the displacement impedance function of the top of the $j$ th pile segment or fictitious soil pile segment can be founded as

$$
\begin{aligned}
& \left.Z_{p j}\right|_{z=h_{j}} \\
& =\frac{-\left.\left[E_{p j} A_{p j}\left(\partial U_{j}(z, s) / \partial z\right)+A_{p j} \delta_{p j} s\left(\partial U_{j}(z, s) / \partial z\right)\right]\right|_{z=h_{j}}}{\left.U_{j}(z, s)\right|_{z=h_{j}}} \\
& =-\frac{\rho_{p j} A_{p j} V_{p j}\left(1+\left(\delta_{p j} / E_{p j}\right) s\right) \bar{\lambda}_{j} \tan \left(\bar{\lambda}_{j}-\phi_{j}\right)}{t_{j}},
\end{aligned}
$$

where $\phi_{j}=\arctan \left(Z_{p(j-1)} t_{j} / \rho_{p j} A_{p j} V_{p j} \bar{\lambda}_{j}\left(1+\left(\delta_{p j} / E_{p j}\right) s\right)\right)$.

Through further recursion, the displacement impedance function at the pile head can be expressed as

$$
\begin{aligned}
& \left.Z_{p m}\right|_{z=0} \\
& =\frac{-\left.\left[E_{p m} A_{p m}\left(\partial U_{m}(z, s) / \partial z\right)+A_{p m} \delta_{p m} s\left(\partial U_{m}(z, s) / \partial z\right)\right]\right|_{z=0}}{\left.U_{m}(z, s)\right|_{z=0}} \\
& =-\frac{\rho_{p m} A_{p m} V_{p m}\left(1+\left(\delta_{p m} / E_{p m}\right) s\right) \bar{\lambda}_{m} \tan \left(\bar{\lambda}_{m}-\phi_{m}\right)}{t_{m}},
\end{aligned}
$$

where $\phi_{m}=\arctan \left(Z_{p(m-1)} t_{m} / \rho_{p m} A_{p m} V_{p m} \bar{\lambda}_{m}\left(1+\left(\delta_{p m} /\right.\right.\right.$ $\left.\left.E_{p m}\right) s\right)$.

Following the definition of Wang et al. [9], the velocity transit function at the pile head can be expressed as

$$
\begin{aligned}
& H_{v}=s \times \frac{1}{Z_{p m}} \\
& =-\frac{s t_{m}}{\rho_{p m} A_{p m} V_{p m}\left(1+\left(\delta_{p m} / E_{p m}\right) s\right) \bar{\lambda}_{m} \tan \left(\bar{\lambda}_{m}-\phi_{m}\right)} .
\end{aligned}
$$

Letting $s=\mathrm{i} \omega$ and substituting it into (16), the velocity response in the frequency domain at the pile head can be derived as

$$
\begin{aligned}
& H_{v}(\mathrm{i} \omega)=-\frac{1}{\rho_{p m} A_{p m} V_{p m}} \\
& \cdot \frac{\mathrm{i} \bar{\omega} \bar{t}_{m}}{\left(1+\left(\delta_{p m} / E_{p m}\right) \mathrm{i} \bar{\omega}\right) \bar{\lambda}_{m} \tan \left(\bar{\lambda}_{m}-\phi_{m}\right)}
\end{aligned}
$$

Nondimensionalizing expression (17) yields the dimensionless velocity admittance of the pile head:

$$
\left|H_{v}^{\prime}\right|=\left|\frac{\mathrm{i} \bar{\omega} \bar{t}_{m}}{\left(1+\left(\delta_{p m} / E_{p m}\right) \mathrm{i} \bar{\omega}\right) \bar{\lambda}_{m} \tan \left(\bar{\lambda}_{m}-\phi_{m}\right)}\right|,
$$

where $\bar{\omega}=T_{c} \omega$ and $\bar{t}_{m}=t_{m} / T_{c}$ depict the dimensionless frequency and dimensionless propagation time of elastic longitudinal wave in the $m$ th pile segment, respectively.

By virtue of the inverse Fourier transform, the velocity response at the pile head is derived as $V(t)=$ $\operatorname{IFT}\left[Q(\omega) H_{v}(\mathrm{i} \omega)\right]$ in the time domain, where $Q(\omega)$ represents the Fourier transform of $q(t)$ with respect to time. In particular, for the low-strain integrity testing of pile, the vertical excitation can be regarded as a semisinusoidal force as follows:

$$
q(t)= \begin{cases}Q_{\max } \sin \left(\frac{\pi}{T_{0}} t\right), & t \in\left(0, T_{0}\right) \\ 0, & t \geq T_{0},\end{cases}
$$

where $T_{0}$ and $Q_{\max }$ denote the pulse width and maximum amplitude of the excitation, respectively. The velocity response of pile head in the time domain can be derived as

$$
\begin{aligned}
& V(t)=-\frac{1}{2} \frac{Q_{\max }}{\rho_{p m} A_{p m} V_{p m}} \\
& \quad \cdot \int_{-\infty}^{\infty} \frac{\mathrm{i} \bar{\omega} \bar{t}_{m}}{\left(1+\left(\delta_{p m} / E_{p m} T_{c}\right) \mathrm{i} \bar{\omega}\right) \bar{\lambda}_{m} \tan \left(\bar{\lambda}_{m}-\phi_{m}\right)} \frac{\bar{T}_{0}}{\pi^{2}-\bar{T}_{0}^{2} \bar{\omega}^{2}}(1 \\
& \left.\quad+e^{-\mathrm{i} \bar{\omega} \bar{T}_{0}}\right) e^{\mathrm{i} \bar{\omega} \bar{t} \mathrm{~d} \bar{\omega} .}
\end{aligned}
$$

The dimensionless velocity response of pile head in the time domain is expressed as

$$
\begin{aligned}
V^{\prime} & =-\frac{1}{2} \\
& \cdot \int_{-\infty}^{\infty} \frac{\mathrm{i} \bar{\omega} \bar{t}_{m}}{\left(1+\left(\delta_{p m} / E_{p m} T_{c}\right) \mathrm{i} \bar{\omega}\right) \bar{\lambda}_{m} \tan \left(\bar{\lambda}_{m}-\phi_{m}\right)} \frac{\bar{T}_{0}}{\pi^{2}-\bar{T}_{0}^{2} \bar{\omega}^{2}}(1 \\
& \left.+e^{-\mathrm{i} \bar{\omega} \bar{T}_{0}}\right) e^{\mathrm{i} \bar{\omega} \bar{t}} \mathrm{~d} \bar{\omega}
\end{aligned}
$$

where $\bar{T}_{0}=T_{0} / T_{c}, \bar{t}=t / T_{c}$, $t$, and $\bar{\delta}_{p m}=\delta_{p m} /\left(E_{p m} T_{c}\right)$ denote the dimensionless pulse width, dimensionless time, time, and dimensionless viscous damping coefficient, respectively.

\section{Parametric Study and Discussion}

In this section, the vertical dynamic response of variable cross-section and variable modulus pile is systematically investigated, which can provide the theoretical basis for various methods of dynamic pile testing. In order to focus on the influence of variable impedance on the vertical dynamic response of pile, the surrounding soil is set to be homogeneous in the following analysis. For practical engineering, it only needs to divide the surrounding soil into finite layers according to the actual soil conditions. Unless otherwise specified, the mass density and shear wave velocity 


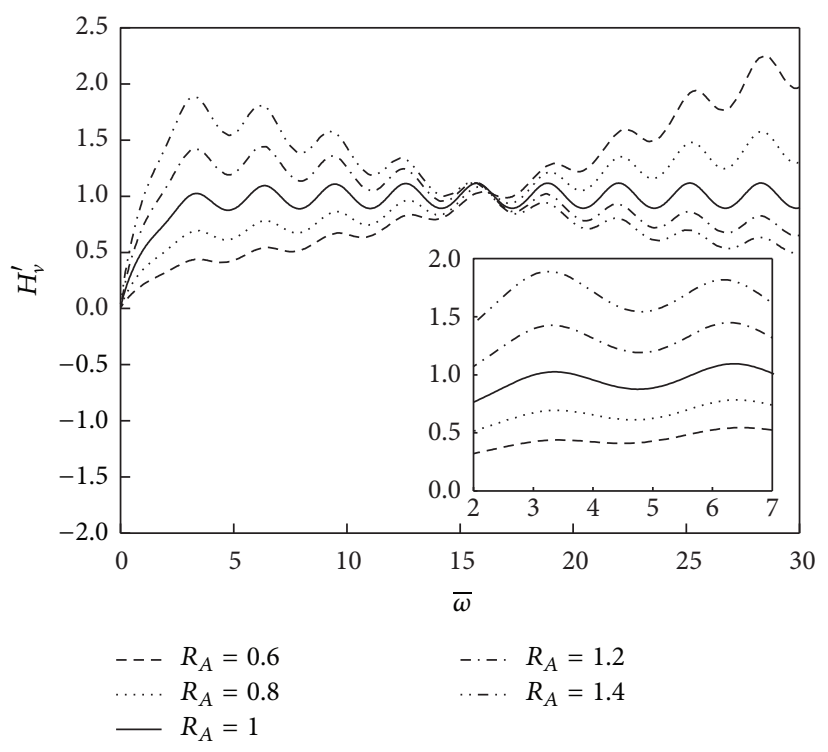

(a) Velocity admittance curves

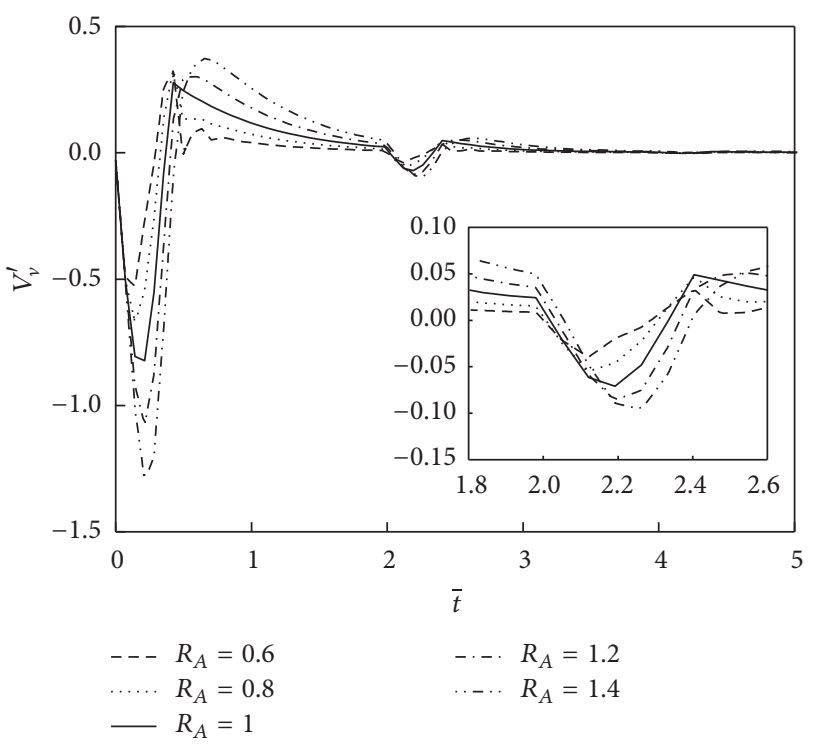

(b) Reflected wave signal curves

FIGURE 2: Influence of the variation degree of variable cross-section segment on the vertical dynamic response of pile head for Case 1.

of pile surrounding soil are given as $1800 \mathrm{~kg} / \mathrm{m}^{3}$ and $180 \mathrm{~m} / \mathrm{s}$, respectively. The mass density, shear wave velocity, Poisson's ratio, viscoelastic damping coefficient, and thickness of pile end soil are $2000 \mathrm{~kg} / \mathrm{m}^{3}, 220 \mathrm{~m} / \mathrm{s}, 0.35,1000 \mathrm{~N} \cdot \mathrm{m}^{-3} \cdot \mathrm{s}$, and 3 times pile diameter, respectively.

\subsection{Vertical Vibration Characteristics of Variable Cross-Section} Pile. According to engineering experience, the variation of cross-section at different locations will result in different vertical vibration characteristics of pile. Therefore, the influence of bulging and necking at different locations along the pile shaft on the vertical vibration characteristics at pile head is investigated in the following analyses. The length, radius, mass density, and longitudinal wave velocity of pile are given as $20 \mathrm{~m}, 0.5 \mathrm{~m}, 2500 \mathrm{~kg} / \mathrm{m}^{3}$, and $3800 \mathrm{~m} / \mathrm{s}$, respectively.

Case 1 (variable cross-section segment at the top of pile shaft). For this engineering condition, the pile shaft is divided into two segments, which are marked by 1 and 2 from pile end to pile top. Segment 1 has a uniform cross-section and satisfies the design requirements with a length of $19 \mathrm{~m}$, and segment 2 has a variable cross-section with a length of $1 \mathrm{~m}$. Denote the variable cross-section ratio to describe the variable crosssection degree of pile shaft; that is, $R_{A}$ represents the ratio of actual radius to design radius. $R_{A}>1, R_{A}<1$, and $R_{A}=1$ represent the bulging segment, necking segment, and uniform segment, respectively.

Figure 2 shows the influence of the variation degree of variable cross-section segment at pile head on the vertical dynamic response of pile head. As illustrated in Figure 2(a), compared with the uniform cross-section pile, the formant amplitude of velocity admittance curves of pile with necking segment at pile head becomes smaller within low frequency range, but the formant amplitude of velocity admittance curves becomes larger within high frequency range. In contrast, compared with the uniform cross-section pile, the formant amplitude of velocity admittance curves of pile with bulging segment at pile head becomes larger within low frequency range, but the formant amplitude of velocity admittance curves becomes smaller within high frequency range. It can also be seen that the larger the necking degree or bulging degree of variable cross-section segment, the more obvious the variation of the formant amplitude of velocity admittance curves of necking pile or bulging pile. From Figure 2(b), compared with the uniform cross-section pile, the peak values of incident wave signals and preliminary orthokinetic reflected signals from pile end in the reflected wave signal curves of pile with necking segment at pile head become smaller, and the larger the necking degree of variable cross-section segment, the larger the reducing degree of peak value. It can also be seen that the signals between the incident wave and the preliminary orthokinetic reflected wave from pile end tend to inclining downward, and the larger the necking degree of variable cross-section segment at pile head, the more obvious the inclining phenomena. By contrast, for the pile with bulging segment at pile head, the existence of bulging segment at pile head will enlarge the peak values of incident wave signals and preliminary orthokinetic reflected signals from pile end in the reflected wave signal curves. The larger the bulging degree of variable cross-section segment, the larger the increasing range of peak value. It is also observed that the signals between the incident wave and the preliminary orthokinetic reflected wave from pile end tend to inclining upward, and the larger the bulging degree of variable cross-section segment at pile head, the more obvious the inclining phenomena.

Case 2 (variable cross-section segment at the end of pile shaft). Owing to the variation of cross-section, the pile shaft 


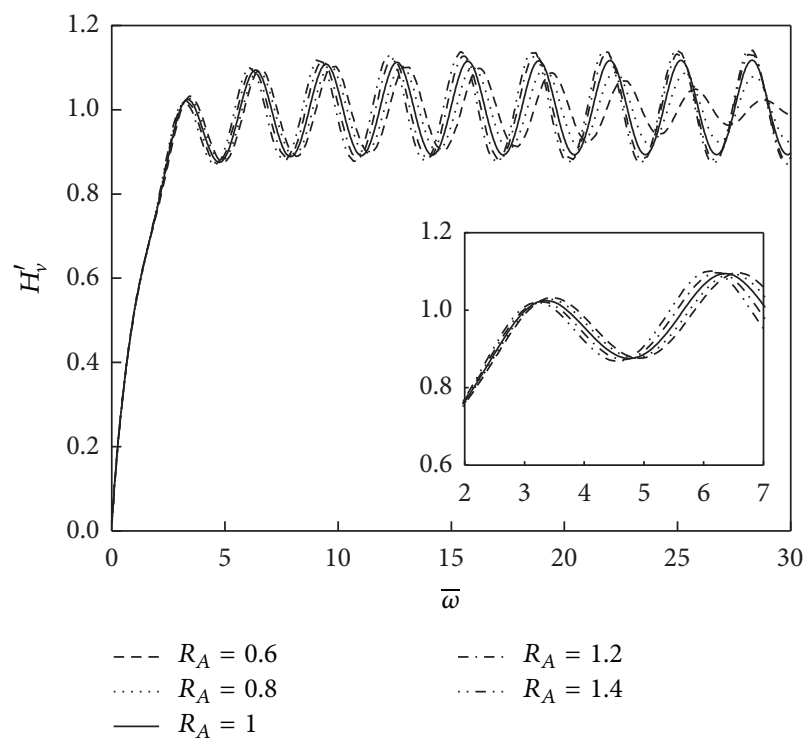

(a) Velocity admittance curves

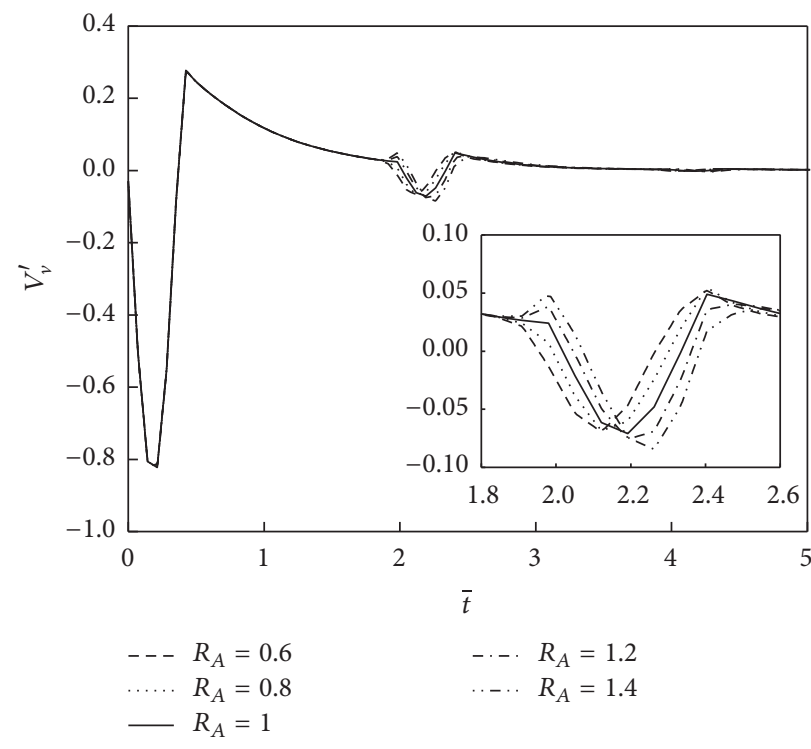

(b) Reflected wave signal curves

FIGURE 3: Influence of the variation degree of variable cross-section segment on the vertical dynamic response of pile head for Case 2.

is also divided into two segments, which are marked by 1 and 2 from pile end to pile top. Segment 1 has a variable crosssection with a length of $1 \mathrm{~m}$, and segment 2 has a uniform cross-section and satisfies the design requirements with a length of $19 \mathrm{~m}$. The other parameters are the same as those shown in Case 1.

Figure 3 illustrates the influence of the variation degree of variable cross-section segment at pile end on the vertical dynamic response of pile head. As shown in Figure 3(a), compared with the uniform cross-section pile, the resonant frequency of the velocity admittance curves of pile with necking segment at pile end gradually increases with the increase of necking degree of variable cross-section segment. The formant amplitude of velocity admittance curves remains basically invariable within low frequency range, but the formant amplitude of velocity admittance curves within high frequency range gradually decreases as the necking degree of variable cross-section segment increases. For the case of pile with bulging segment at pile end, the resonant frequency of the velocity admittance curves gradually decreases as the bulging degree of variable cross-section segment increases. The formant amplitude of velocity admittance curves within high frequency range gradually increases with the increase of the necking degree of variable cross-section segment, but the formant amplitude of velocity admittance curves within low frequency range remains basically invariable. As seen in Figure 3(b), compared with the uniform cross-section pile, the peak values of preliminary orthokinetic reflected signals from pile end in the reflected wave signal curves of pile with necking segment at pile end become smaller, and the arrival time of reflected signals from pile end will be ahead. For the case of pile with bulging segment at pile end, reverse reflected signals with small amplitude will occur before the preliminary orthokinetic reflected signals from pile end. The peak values of preliminary orthokinetic reflected signals from pile end become larger, and the arrival time of reflected signals from pile end will be delayed. It can also be observed that the larger the necking degree or bulging degree of variable cross-section segment, the more obvious the above phenomena.

Case 3 (variable cross-section segment at the middle part of pile shaft). For Case 3, the pile shaft is divided into three segments, which are marked by 1, 2, and 3 from pile end to pile top. Segments 1 and 3 have a uniform cross-section and satisfy the design requirements with a length of $9.5 \mathrm{~m}$, and segment 2 has a variable cross-section with a length of $1 \mathrm{~m}$. The other parameters are the same as those given in Case 1.

Figure 4 depicts the influence of the variation degree of variable cross-section segment at the middle part of pile shaft on the vertical dynamic response of pile head. From Figure 4(a), compared with the uniform cross-section pile, the oscillatory part of the velocity admittance curves displays increasing complex characteristics of nonuniform peaks with irregular distribution for the pile with necking or bulging segment at the middle part. Therefore, it is difficult to intuitively assess the pile quality from the velocity admittance curves for these conditions. As illustrated in Figure 4(b), for the pile with necking segment at the middle part of pile shaft, the orthokinetic reflected signals at the middle part of pile shaft are first received between the incident wave signals and preliminary orthokinetic reflected signals from pile end, and the reverse reflected signals will occur after the orthokinetic reflected signals. The peak values of preliminary orthokinetic reflected signals from pile end are reduced because of the orthokinetic reflected signals at the middle part of pile shaft. By contrast, for the pile with bulging segment at the middle part of pile shaft, the reverse reflected 


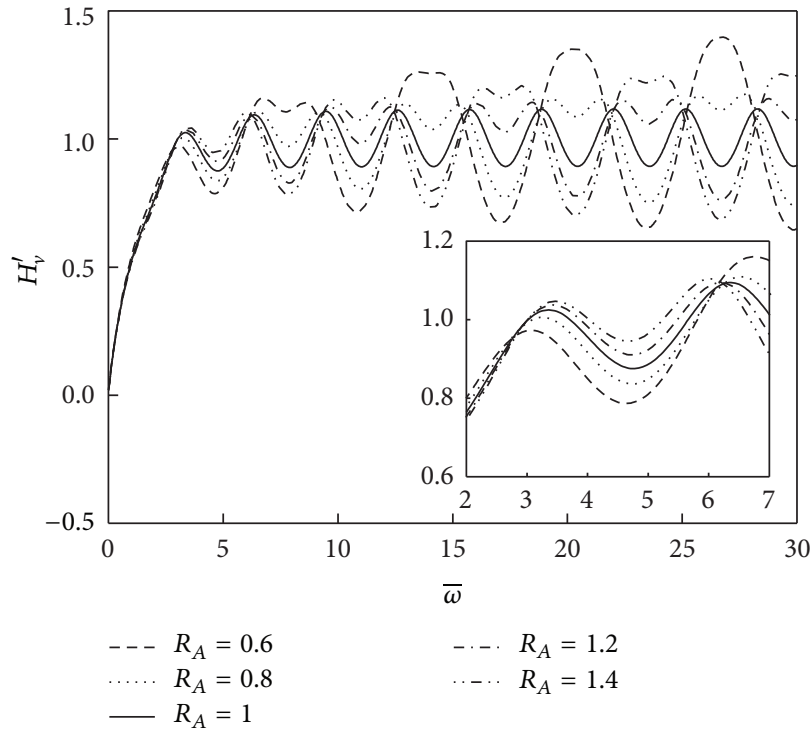

(a) Velocity admittance curves

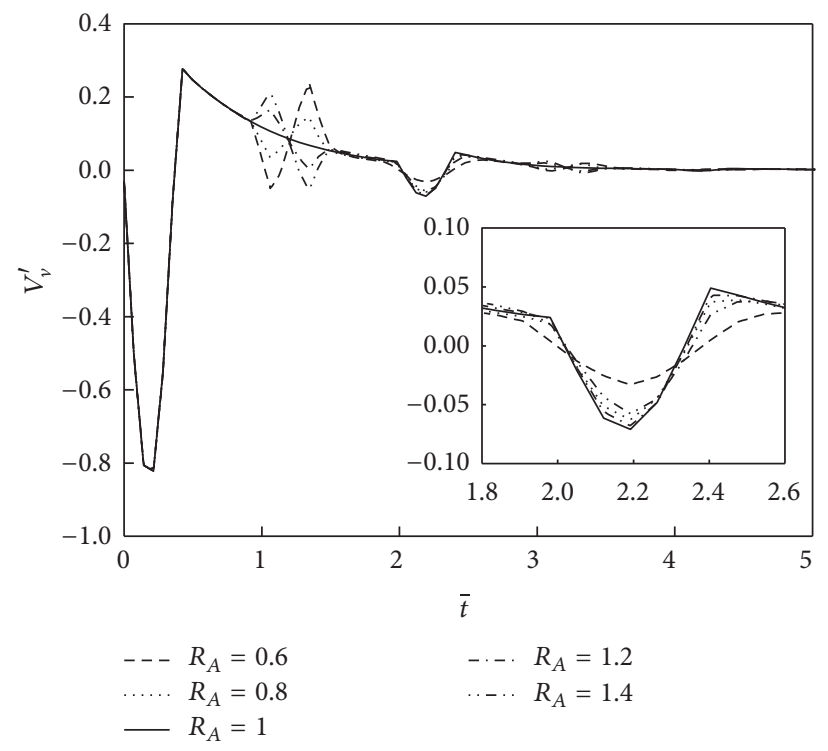

(b) Reflected wave signal curves

FIGURE 4: Influence of the variation degree of variable cross-section segment on the vertical dynamic response of pile head for Case 3.

signals with orthokinetic reflected signals at the middle part of pile shaft are first received between the incident wave signals and preliminary orthokinetic reflected signals from pile end, and the peak values of preliminary orthokinetic reflected signals from pile end are also reduced owing to the orthokinetic reflected signals at the middle part of pile shaft. It can be seen that the larger the necking degree or bulging degree of variable cross-section segment, the more obvious the above phenomena.

Case 4 (variable cross-section segment located between the middle and the top of pile shaft). Similar to Case 3, the pile shaft is also divided into three segments, which are marked by 1,2 , and 3 from pile end to pile top. Segment 1 and segment 3 have a uniform cross-section and satisfy the design requirements, and segment 2 has a variable cross-section. The lengths of each segment are $l_{1}=13 \mathrm{~m}, l_{2}=1 \mathrm{~m}$, and $l_{3}=6 \mathrm{~m}$, respectively. The other parameters are the same as those shown in Case 1.

Figure 5 shows the influence of variation degree of variable cross-section segment located between the middle and the top of pile shaft on the vertical dynamic response of pile head. Similar to Case 3, it is also difficult to estimate the pile quality from the velocity admittance curves for Case 4 because of the complex characteristics of nonuniform peaks with irregular distribution. As depicted in Figure 5(b), for the pile with necking segment located between the middle and the top of pile shaft, the orthokinetic reflected signals with reverse reflected signals will first appear at a distance of $6 \mathrm{~m}$ to the pile top, and the second-order orthokinetic reflected signals with reverse reflected signals caused by the necking segment will be received again at a distance of $12 \mathrm{~m}$ to the pile top. The peak values of the above-mentioned orthokinetic and reverse reflected signals increase as the necking degree of pile segment increases. For the pile with bulging segment located between the middle and the top of pile shaft, the reverse reflected signals with orthokinetic reflected signals will first occur at a distance of $6 \mathrm{~m}$ to the pile top, and the second-order reverse reflected signals with orthokinetic reflected signals caused by the bulging segment will be received again at a distance of $12 \mathrm{~m}$ to the pile top. The peak values of the above-mentioned reverse and orthokinetic reflected signals increase with the increase of the bulging degree of pile segment. It can be found that the larger the necking degree or bulging degree of variable cross-section segment, the larger the peak values of the above-reflected signals.

Case 5 (variable cross-section segment located between the middle and the end of pile shaft). In this case, the pile shaft is also divided into three segments, which are marked by 1,2 , and 3 from pile end to pile top. Segment 1 and segment 3 have a uniform cross-section and satisfy the design requirements, and segment 2 has a variable cross-section. The lengths of each segment are $l_{1}=6 \mathrm{~m}, l_{2}=1 \mathrm{~m}$, and $l_{3}=13 \mathrm{~m}$, respectively. The other parameters are the same as those shown in Case 1.

Figure 6 illustrates the influence of variable degree of variable cross-section segment located between the middle and the end of pile shaft on the vertical dynamic response of pile head. Similar to Cases 3 and 4, it is difficult to evaluate the pile quality from the velocity admittance curves for Case 5 due to the complex characteristics of nonuniform peaks with irregular distribution. As shown in Figure 6(b), for the pile with necking segment located between the middle and the end of pile shaft, the orthokinetic reflected signals 


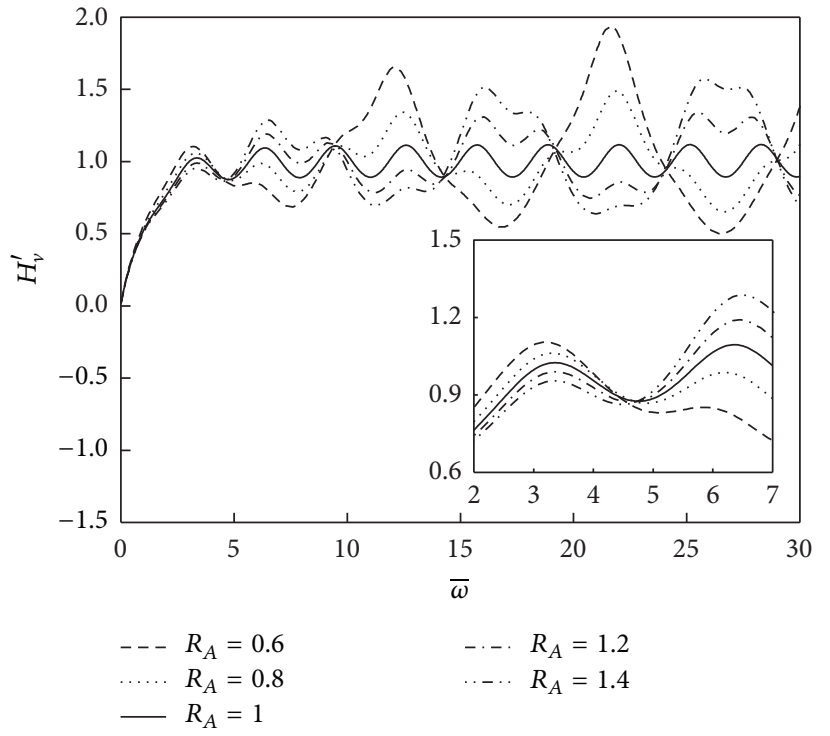

(a) Velocity admittance curves

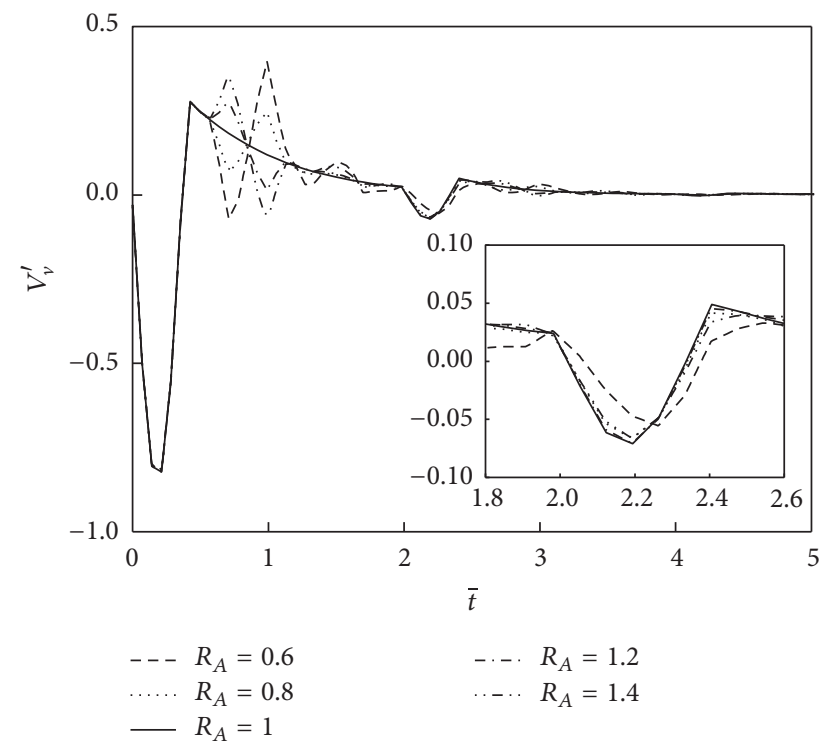

(b) Reflected wave signal curves

FIGURE 5: Influence of the variation degree of variable cross-section segment on the vertical dynamic response of pile head for Case 4.

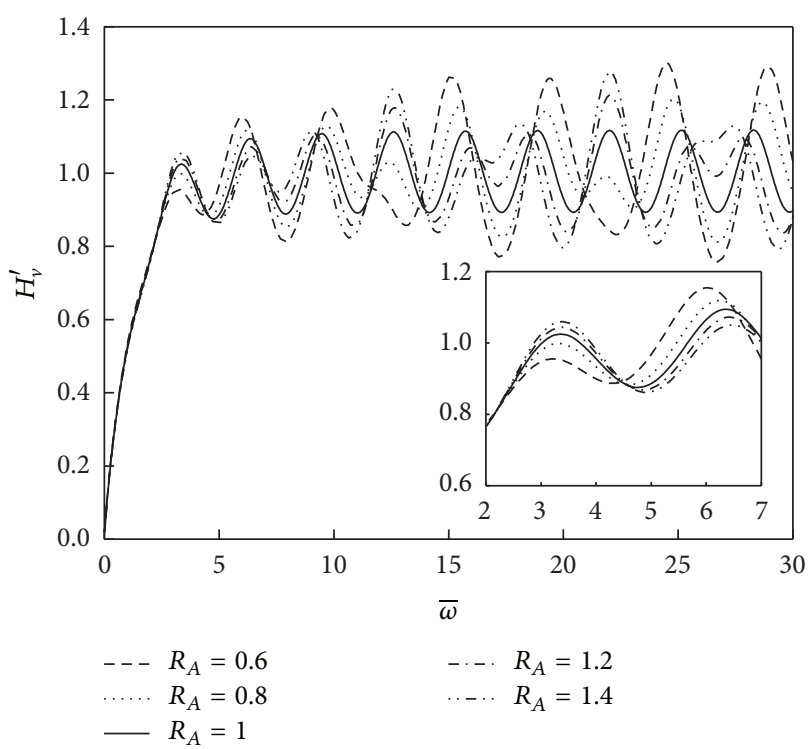

(a) Velocity admittance curves

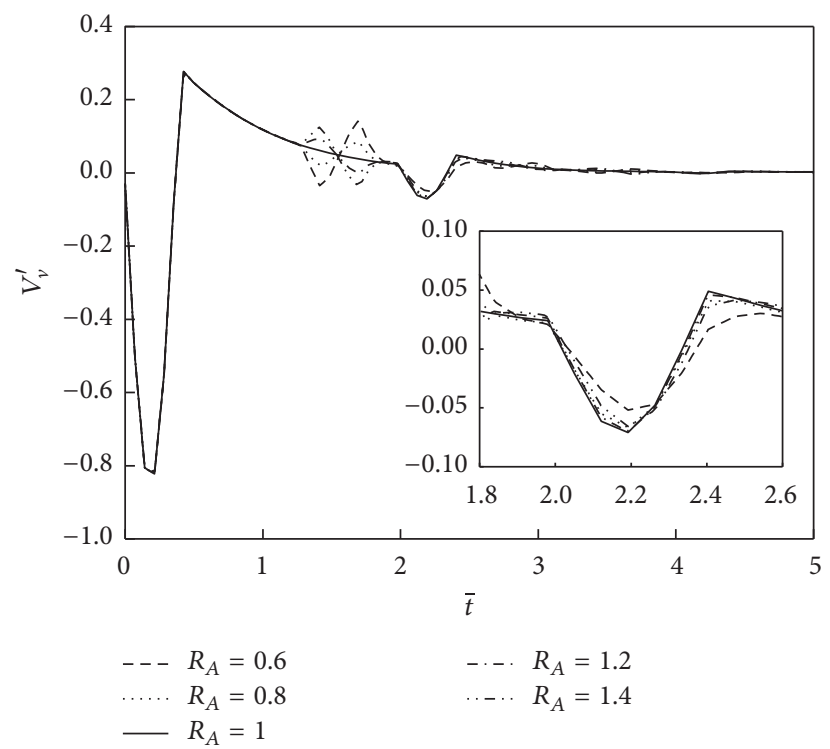

(b) Reflected wave signal curves

FIGURE 6: Influence of the variation degree of variable cross-section segment on the vertical dynamic response of pile head for Case 5.

with reverse reflected signals will occur at a distance of $13 \mathrm{~m}$ to the pile top. The peak values of above-mentioned orthokinetic and reverse reflected signals increase with the increase of the necking degree of pile. For the pile with bulging segment located between the middle and the end of pile shaft, the reverse reflected signals with orthokinetic reflected signals will appear at a distance of $13 \mathrm{~m}$ to the pile top. The peak values of the above-mentioned reverse and orthokinetic reflected signals increase as the bulging degree of pile segment increases. It is worth noting that the larger the necking degree or bulging degree of variable cross-section segment, the larger the peak values of the above-reflected signals.

4.2. Vertical Vibration Characteristics of Variable Modulus Pile. During the construction of bored pile, the modulus of pile may be nonuniform along the pile shaft owing to the immature construction craft, improper construction management, or other adverse factors. Therefore, this section discusses the influence of the location and degree of nonuniform pile segment on the vertical dynamic response of pile head. First, the influence of the location of nonuniform 


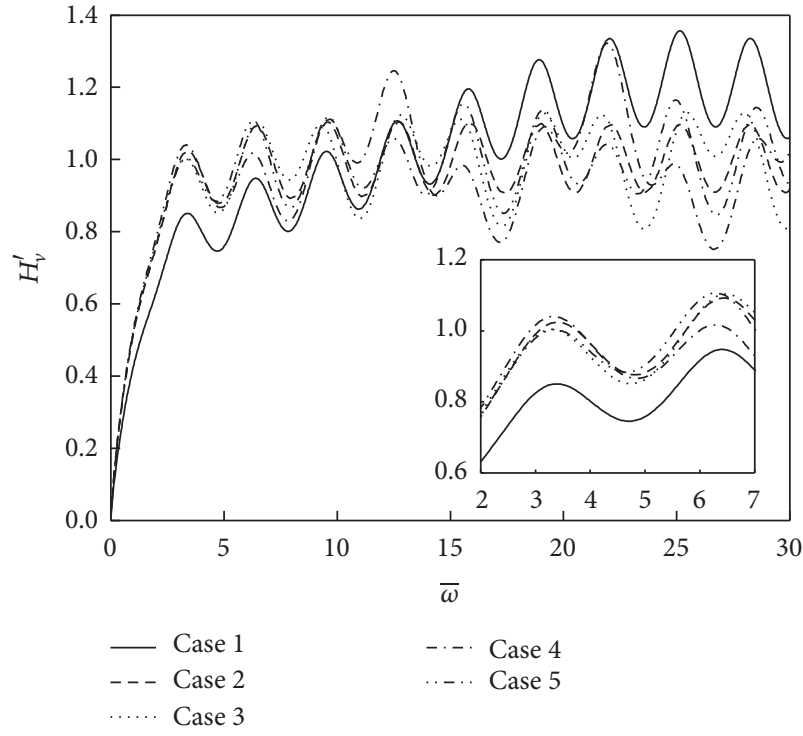

(a) Velocity admittance curves

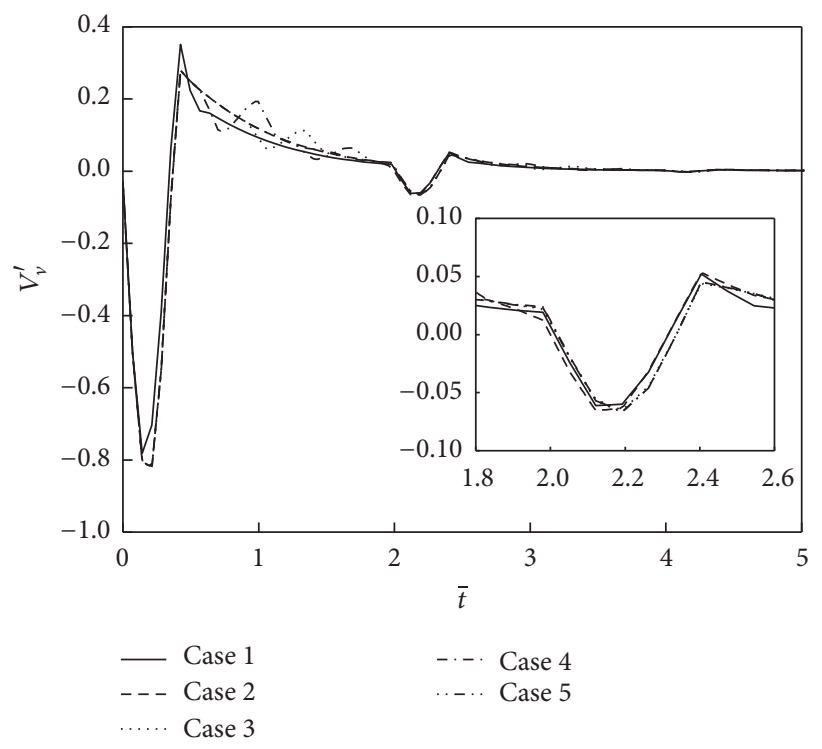

(b) Reflected wave signal curves

FIGURE 7: Influence of the location of nonuniform pile segment on the vertical dynamic response of pile head.

pile segment on the vertical dynamic response of pile is investigated. The location and length of nonuniform pile segment are referred to the five cases shown in Section 4.1. The length, radius, and mass density of pile are $20 \mathrm{~m}, 0.5 \mathrm{~m}$, and $2500 \mathrm{~kg} / \mathrm{m}^{3}$, respectively. The nonuniform characteristic of pile is reflected by varying the longitudinal wave velocity of normal pile segment and nonuniform pile segment, and the longitudinal wave velocity of normal pile segment and nonuniform pile segment are $3800 \mathrm{~m} / \mathrm{s}$ and $3000 \mathrm{~m} / \mathrm{s}$, respectively.

Figure 7 presents the influence of the location of nonuniform pile segment on the vertical dynamic response of pile head. As shown in Figure 7(a), when the nonuniform pile segment is located at the top of pile (Case 1), the formant amplitude of velocity admittance curves gradually increases with the increase of frequency. For the other four cases, the oscillatory part of the velocity admittance curves displays increasing complex characteristics of nonuniform peaks with irregular distribution for the pile with variable modulus segment. From Figure 7(b), the influence of the location of nonuniform pile segment on the vertical dynamic response of pile head for the five cases is basically similar to that of pile with necking segment at corresponding location.

Then, the influence of the degree of nonuniform pile segment on the vertical dynamic response of pile head is further discussed. The pile shaft is divided into three segments, which are marked by 1,2 , and 3 from pile end to pile top. Segment 1 and segment 3 are normal pile segments and have normal modulus satisfying the design requirements; segment 2 has nonnormal modulus. Denote the variable wave impedance ratio to describe the nonuniform degree of pile segment; that is, $R_{V}$ represents the ratio of wave impedance of normal pile segment to that of nonuniform pile segment. $R_{V}>1$ and $R_{V}<1$ mean the increase and decrease of wave impedance in the nonuniform pile segment, respectively. $R_{A}=1$ indicates that the pile is uniform as a whole. The lengths of each segment are $l_{1}=6 \mathrm{~m}, l_{2}=1 \mathrm{~m}$, and $l_{3}=13 \mathrm{~m}$, respectively.

Figure 8 indicates the influence of the degree of nonuniform pile segment on the vertical dynamic response of pile head. As shown in Figure 8(a), similar to the regulation of pile with necking segment or bulging segment at the corresponding location in the pile shaft, there are complex characteristics of nonuniform peaks with irregular distribution in the velocity admittance curves when the wave impedance of nonuniform pile segment increases or decreases. The larger the variation range of wave impedance, the more obvious the complex oscillation. Therefore, it is also difficult to intuitively assess the nonuniform characteristics of pile shaft only from the velocity admittance curves. As depicted in Figure 8(b), as the wave impedance of nonuniform pile segment decreases, the variation regulation of reflected wave curves is basically similar to that of pile with necking segment at corresponding location. Meanwhile, as the wave impedance of nonuniform pile segment increases, the variation regulation of reflected wave curves is basically similar to that of pile with bulging at corresponding location.

\section{Conclusions}

Based on the plane strain model and fictitious soil pile model, this paper derives the analytical solution of velocity admittance in the frequency domain and the corresponding semianalytical solution of the velocity response of pile in the time domain. Based on the solutions, a parametric study is conducted to investigate the vertical dynamic response of pile with variable cross-section segment and variable modulus segment, and the following conclusions are obtained: 


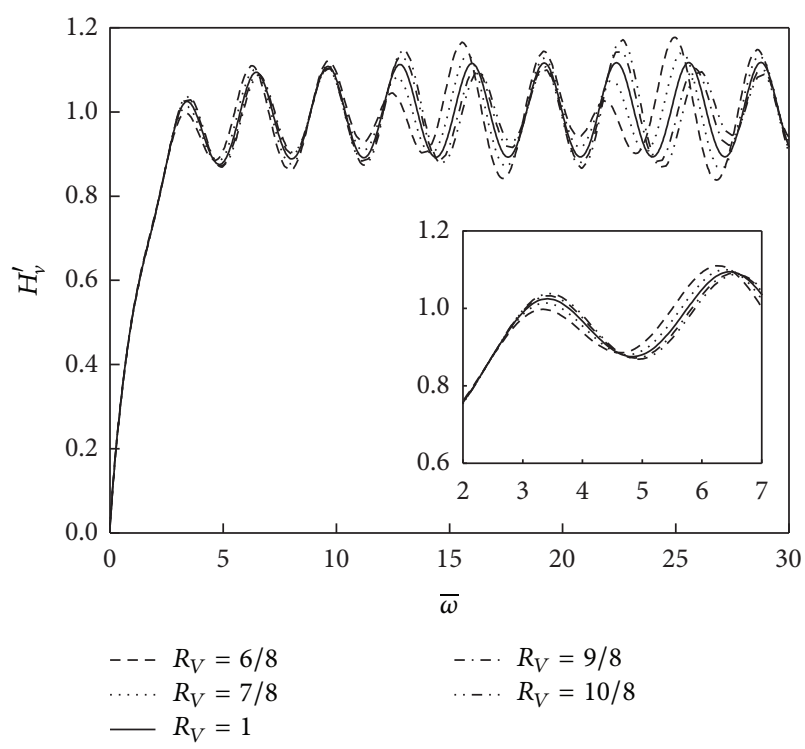

(a) Velocity admittance curves

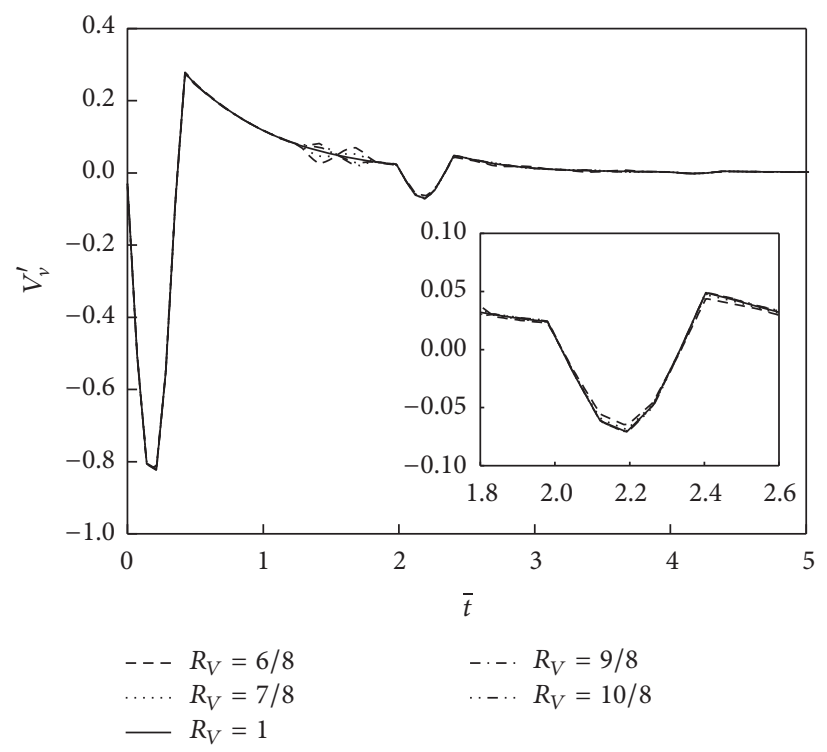

(b) Reflected wave signal curves

FIGURE 8: Influence of the degree of nonuniform pile segment on the vertical dynamic response of pile head.

(1) When there are necking or bulging segments located between the top and the end of pile shaft, the oscillatory part of the velocity admittance curves displays increasing complex characteristics of nonuniform peaks with irregular distribution. Therefore, it is difficult to intuitively assess the construction quality of pile from the velocity admittance curves for these conditions.

(2) For the pile with necking segment or decreasing modulus segment located between the top and the end of pile shaft, the orthokinetic reflected signals are first received between the incident wave signals and preliminary orthokinetic reflected signals from pile end, and the reverse reflected signals will occur after the orthokinetic reflected signals.

(3) For the pile with bulging segment or increasing modulus segment located between the top and the end of pile shaft, the reverse reflected signals will first appear between the incident wave signals and preliminary orthokinetic reflected signals from pile end, and the orthokinetic reflected signals are received after the reverse reflected signals.

(4) The larger the necking degree or bulging degree of variable cross-section segment, the larger the peak values of the reflected signals between the incident wave signals and preliminary orthokinetic reflected signals from pile end.

(5) The larger the variation range of the modulus of variable modulus pile segment, the larger the peak values of the reflected signals between the incident wave signals and preliminary orthokinetic reflected signals from pile end.

\section{Conflicts of Interest}

The authors declare that they have no conflicts of interest.

\section{Acknowledgments}

This research is funded by the National Natural Science Foundation of China (Grants nos. 51309207, 51322807, and 51678547) and the China Postdoctoral Science Foundation Funded Project (Grant no. 2016M600711). The authors also wish to acknowledge the support of the Research Funds provided by MOE Engineering Research Center of RockSoil Drilling \& Excavation and Protection (Grant no. 201402) and the Fundamental Research Funds for the Central Universities-Cradle Plan for 2015 (Grant no. CUGL150411).

\section{References}

[1] S. T. Liao and J. M. Roesset, "Dynamic response of intact piles to impulse loads," International Journal for Numerical and Analytical Methods in Geomechanics, vol. 21, no. 4, pp. 255-275, 1997.

[2] L. Yanlong, L. Shouyi, Y. Yang, and T. Xing, “Temperature stress and surface insulation measures of concrete face slabs during cold wave period," International Journal of Civil Engineering, vol. 13, no. 4, pp. 501-507, 2015.

[3] Y. Li, Y. Sun, B. Li, and Z. Xu, "Penalty function-based method for obtaining a reliability indicator of gravity dam stability," Computers and Geotechnics, vol. 81, pp. 19-25, 2017.

[4] H. Tian, M. Ziegler, and T. Kempka, "Physical and mechanical behavior of claystone exposed to temperatures up to 1000 ॰C," International Journal of Rock Mechanics and Mining Sciences, vol. 70, pp. 144-153, 2014. 
[5] H. Van Koten, P. Middendorp, and P. Van Brederode, "An analysis of dissipative wave propagation in a pile," in International Seminar on the Application of Stress-Wave Theory on Piles, Stockholm, A.A. Balkema, Rotterdam, The Netherlands, 1980.

[6] M. F. Randolph and A. J. Deeks, "Dynamic and static soil models for axial response," in Proceedings of the 4th International Conference on the Application of Stress Wave Theory to Piles, pp. 3-14, The Hague, The Netherlands, September 1992.

[7] O. Michaelides, G. Gazetas, G. Bouckovalas, and E. Chrysikou, "Approximate non-linear dynamic axial response of piles," Geotechnique, vol. 48, no. 1, pp. 33-53, 1998.

[8] Y. Yesilce and H. H. Catal, "Free vibration of piles embedded in soil having different modulus of subgrade reaction," Applied Mathematical Modelling, vol. 32, no. 5, pp. 889-900, 2008.

[9] K. Wang, W. Wu, Z. Zhang, and C. J. Leo, "Vertical dynamic response of an inhomogeneous viscoelastic pile," Computers and Geotechnics, vol. 37, no. 4, pp. 536-544, 2010.

[10] Q.-Q. Zhang and Z.-M. Zhang, "A simplified nonlinear approach for single pile settlement analysis," Canadian Geotechnical Journal, vol. 49, no. 11, pp. 1256-1266, 2012.

[11] Q.-Q. Zhang, S.-W. Liu, S.-M. Zhang, J. Zhang, and K. Wang, "Simplified non-linear approaches for response of a single pile and pile groups considering progressive deformation of pile-soil system," Soils and Foundations, vol. 56, no. 3, pp. 473-484, 2016.

[12] M. Novak, "Dynamic stiffness and damping of piles," Canadian Geotechnical Journal, vol. 11, no. 4, pp. 574-598, 1974.

[13] R. K. N. D. Rajapakse and A. H. Shah, "On the longitudinal harmonic motion of an elastic bar embedded in an elastic halfspace," International Journal of Solids and Structures, vol. 23, no. 2, pp. 267-285, 1987.

[14] S. M. Mamoon and P. K. Banerjee, "Time-domain analysis of dynamically loaded single piles," Journal of Engineering Mechanics, vol. 118, no. 1, pp. 140-160, 1992.

[15] M. H. El Naggar and M. Novak, "Nonlinear analysis for dynamic lateral pile response," Soil Dynamics and Earthquake Engineering, vol. 15, no. 4, pp. 233-244, 1996.

[16] G. Militano and R. K. N. D. Rajapakse, "Dynamic response of a pile in a multi-layered soil to transient torsional and axial loading," Geotechnique, vol. 49, no. 1, pp. 91-109, 1999.

[17] W. Wu, G. Jiang, B. Dou, and C. J. Leo, "Vertical dynamic impedance of tapered pile considering compacting effect," Mathematical Problems in Engineering, vol. 2013, Article ID 304856, 9 pages, 2013.

[18] T. Nogami and M. Novak, "Soil-pile interaction in vertical vibration," Earthquake Engineering \& Structural Dynamics, vol. 4, no. 3, pp. 277-293, 1976.

[19] T. Nogami and K. Konagai, "Time domain axial response of dynamically loaded single piles," Journal of Engineering Mechanics, vol. 112, no. 11, pp. 1241-1252, 1986.

[20] T. Senjuntichai, S. Mani, and R. K. N. D. Rajapakse, "Vertical vibration of an embedded rigid foundation in a poroelastic soil," Soil Dynamics and Earthquake Engineering, vol. 26, no. 6-7, pp. 626-636, 2006.

[21] C. B. Hu, K. H. Wang, and K. H. Xie, "Time domain analysis of vertical dynamic response of a pile considering the effect of soilpile interaction," Chinese Journal of Computational Mechanics, vol. 21, no. 8, pp. 392-399, 2004 (Chinese).

[22] K. Wang, Z. Zhang, C. J. Leo, and K. Xie, "Dynamic torsional response of an end bearing pile in saturated poroelastic medium," Computers and Geotechnics, vol. 35, no. 3, pp. 450458, 2008.
[23] W. B. Wu, K. H. Wang, Z. Q. Zhang, and C. J. Leo, "Soilpile interaction in the pile vertical vibration considering true three-dimensional wave effect of soil," International Journal for Numerical and Analytical Methods in Geomechanics, vol. 37, no. 17, pp. 2860-2876, 2013.

[24] W. Wu, G. Jiang, S. Huang, and C. J. Leo, "Vertical dynamic response of pile embedded in layered transversely isotropic soil," Mathematical Problems in Engineering, vol. 2014, Article ID 126916, 12 pages, 2014.

[25] C. Zheng, H. Liu, X. Ding, G. P. Kouretzis, S. W. Sloan, and H. G. Poulos, "Non-axisymmetric response of piles in low-strain integrity testing," Géotechnique, vol. 67, no. 2, pp. 181-186, 2017.

[26] C. Zheng, G. P. Kouretzis, X. Ding, H. Liu, and H. G. Poulos, "Three-dimensional effects in low-strain integrity testing of piles: analytical solution," Canadian Geotechnical Journal, vol. 53, no. 2, pp. 225-235, 2015. 


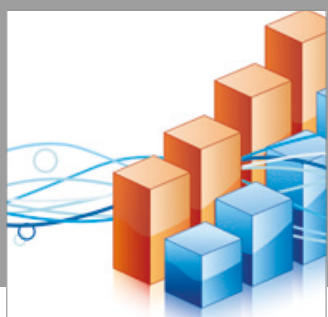

Advances in

Operations Research

vatersals

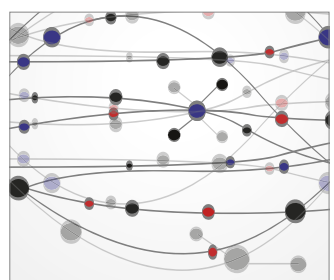

\section{The Scientific} World Journal
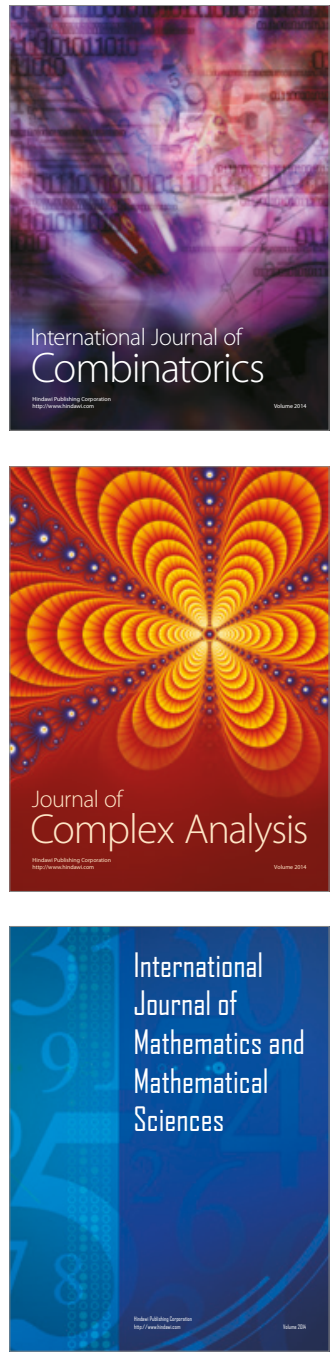
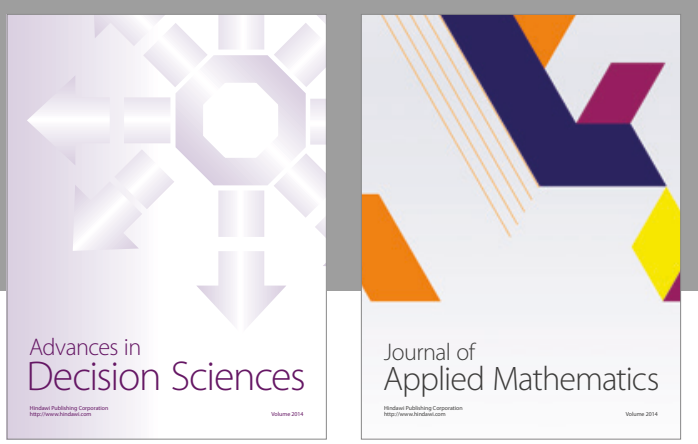

Algebra

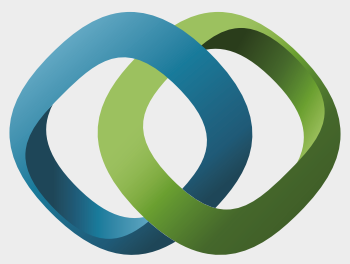

\section{Hindawi}

Submit your manuscripts at

https://www.hindawi.com
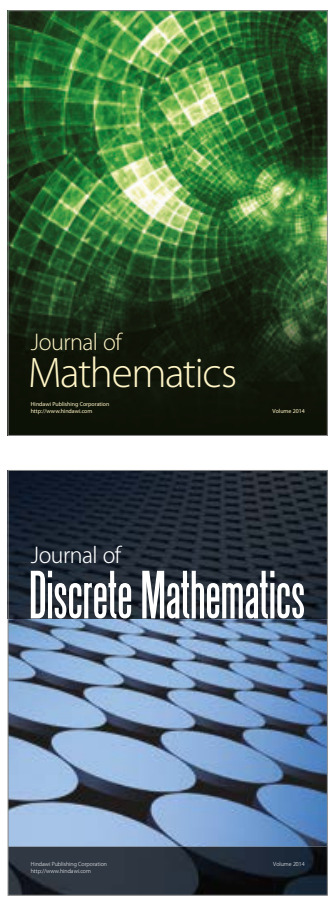

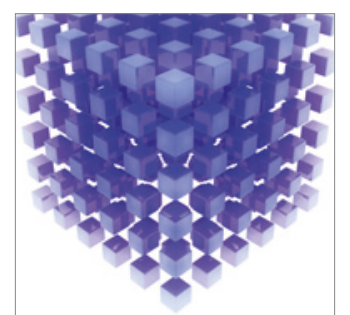

Mathematical Problems in Engineering
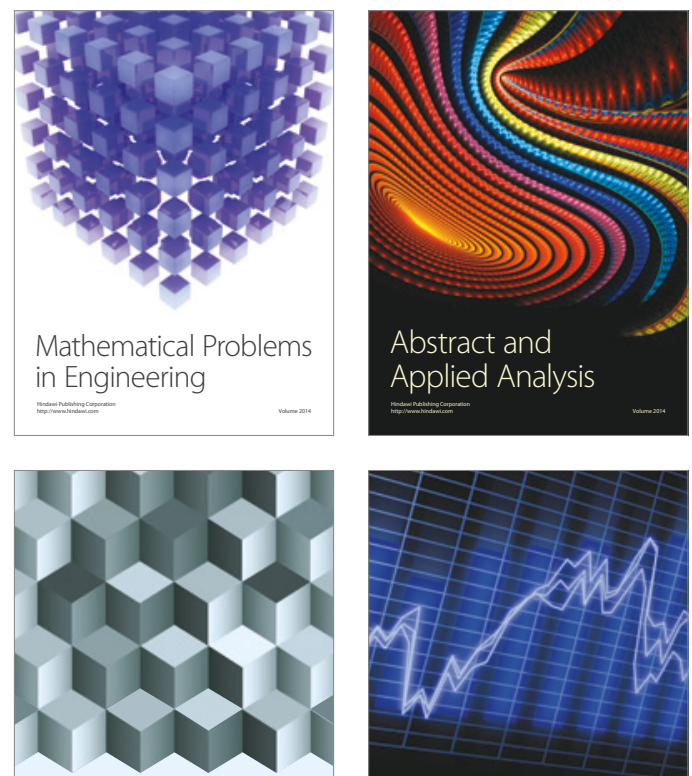

Journal of

Function Spaces

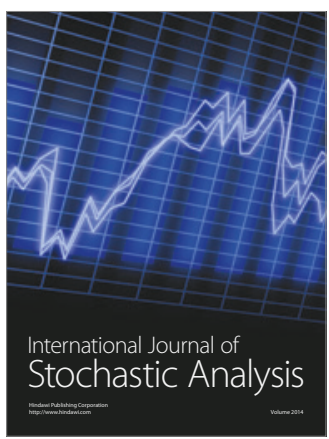

Probability and Statistics
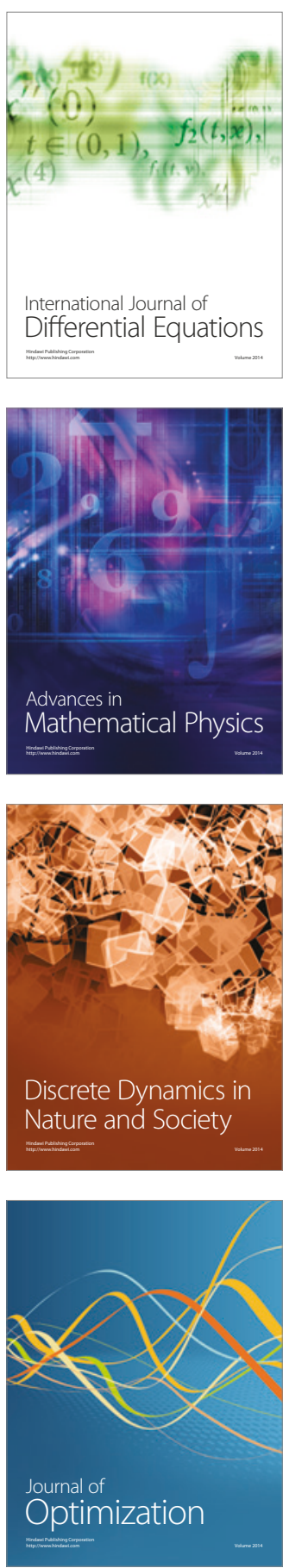